Check for updates

Cite this: Chem. Sci., 2018, 9, 4689

\title{
Hydrogen gas generation using a metal-free fluorinated porphyrin $\dagger$
}

\author{
Yanyu Wu, Nancy Rodríguez-López and Dino Villagrán (DD* \\ Free-base meso-tetra(pentafluorophenyl)porphyrin, 1, is electrocatalytically active for hydrogen gas \\ generation in the presence of $p$-toluenesulfonic acid. The electrochemical potential of hydrogen \\ evolution ( $-1.31 \mathrm{~V}$ vs. $\mathrm{Fc} / \mathrm{Fc}^{+}$in THF) is comparable to those of metal containing electrocatalysts such as \\ metallated porphyrins or other metallated macrocycles. Combining experimental observations and DFT \\ computations, we propose the most favorable hydrogen generation mechanism to be a (1) reduction, (2) \\ protonation, (3) reduction, (4) protonation (E-P-E-P) pathway.
}

Received 9th January 2018

Accepted 20th April 2018

DOI: $10.1039 / \mathrm{c} 8 \mathrm{sc00093j}$

rsc.li/chemical-science

hydrogen bonds and can also be electrochemically active. In

\section{Introduction}

Production of molecular hydrogen through electrochemical hydrogen evolution reactions (HERs) is crucial for the development of several clean-energy technologies. Such reactions require efficient and robust catalysts that are able to increase the reaction kinetics by lowering the high activation energy of hydrogen generation. ${ }^{1-3}$ Platinum metal is a highly efficient catalyst which is able to generate high exchange current densities at practically zero overpotential. ${ }^{1,45}$ However, platinum is scarce and expensive. ${ }^{4}$ Thus, replacement of platinum by other cost-effective alternatives with promisingly high electrocatalytic activity is necessary for the sustainable production of hydrogen gas. ${ }^{6-8}$ Currently, nearly all HER catalysts developed are based on earth-abundant transition metals such as Mo, Co, Ni, Fe and their complexes. ${ }^{6-15}$ HER catalytic systems utilizing metal-free compounds are uncommon; ${ }^{16,17}$ however, organic-based hydrogen generation catalysts may provide superior synthetic flexibility, lower manufacturing costs, and greater chemical stability.

Metalloporphyrins have been well investigated for their ability to generate $\mathrm{H}_{2}$ both electrochemically and photochemically. ${ }^{18-23}$ In metallated HER electrocatalysts, the metal center is the active site in the hydrogen production process by participating in the formation of metal-hydrogen bonds and is the redox center in the multielectron reduction process. ${ }^{19,24-26}$ In comparison, freebase porphyrins are known to exhibit rich multielectron redox chemistry. ${ }^{27,28}$ Two basic imine nitrogen atoms in the porphyrin core can produce a diprotonated porphyrin species. ${ }^{29,30}$ Thus, free-base porphyrins have the ability to form covalent nitrogen-

Department of Chemistry and Biochemistry, The University of Texas at El Paso, El Paso, TX 79968, USA. E-mail: dino@utep.edu

$\dagger$ Electronic supplementary information (ESI) available: Cyclic voltammograms for $p$-toluenesulfonic acid in THF without the presence of catalysts. Details of the bulk electrolysis experiments. Calculated thermodynamic quantities and additional benchmark details. Cartesian coordinates of the DFT optimized geometries in the gas phase and in solution. See DOI: 10.1039/c8sc00093j addition, the four-nitrogen porphyrin core is perfectly suited for bringing protons in close proximity to lower the activation energy of dihydrogen production by prearranging the transition state of hydrogen-hydrogen bond formation. However, whether a molecular metal-free porphyrin has the ability to exhibit similar and comparable electrocatalytic HER activity to the existing wellstudied metallated macrocyclic complexes has not yet been studied or reported.

In this work we show that free-base meso-tetra(pentafluorophenyl)porphyrin, $\mathbf{1}$, is a HER electrocatalyst in the presence of $p$-toluenesulfonic (tosic) acid as the proton source with THF as the solvent. The electrocatalytic activity of $\mathbf{1}$ was estimated by electrochemical studies and $\mathrm{H}_{2}$ gas analysis in acidic solutions. Spectroscopic measurements including UV-vis spectra and spectroelectrochemical studies reveal the spectral signatures of the intermediates during the catalysis giving insight into the mechanism of $\mathrm{H}_{2}$ generation. In addition, density functional theory (DFT) calculations were performed to provide further support to the mechanistic HER behavior of $\mathbf{1}$.

\section{Experimental section}

\section{Materials}

All reagents used for synthesis were purchased from SigmaAldrich. Pyrrole was freshly distilled prior to use. Solvents used for electrochemical studies were dried and degassed through a Pure Process Technology solvent purification system. Tetrabutylammonium hexafluorophosphate $\left(\mathrm{TBAPF}_{6}\right)$ and tosic acid were purchased from Acros Organics. Meso-tetra(pentafluorophenyl)porphyrin and meso-tetraphenylporphyrin were synthesized according to Lindsey's method. ${ }^{31}$

\section{Synthesis of meso-tetra(pentafluorophenyl)porphyrin, 1}

Pentafluorobenzaldehyde ( $3.00 \mathrm{~g}, 0.0153 \mathrm{~mol}$ ) was dissolved in $500 \mathrm{~mL}$ of DCM, followed by addition of pyrrole $(1.04 \mathrm{~g}, 0.0153$ 
mol) dropwise. The mixture was stirred and bubbled with $\mathrm{N}_{2}$ for 15 minutes. Next, $0.500 \mathrm{~mL}$ of $\mathrm{BF}_{3} \cdot \mathrm{Et}_{2} \mathrm{O}$ was added with a glass syringe without exposing to air. After 2 hours, the resulting porphyrinogen was oxidized by adding 2,3-dichloro-5,6dicyanobenzoquinone (DDQ) $(5.00 \mathrm{~g}, 0.0220 \mathrm{~mol})$ and letting it react for 30 minutes. Compound 1 (1.80 g, 24.3\% yield) was obtained after recrystallization and column chromatography purification on silica gel eluted with a mixture of hexane and dichloromethane $(2: 1) .{ }^{1} \mathrm{H}$ NMR $\left(\mathrm{C}_{6} \mathrm{D}_{6}\right): 8.71 \mathrm{ppm}(\mathrm{s}, 8 \mathrm{H})$, $-2.10 \mathrm{ppm}(\mathrm{s}, 2 \mathrm{H}) ;{ }^{19} \mathrm{~F}$ NMR $\left(\mathrm{C}_{6} \mathrm{D}_{6}\right):-161.3 \mathrm{ppm}(\mathrm{t}, 2 \mathrm{~F})$, -150.5 ppm (t, 1F), -137.2 ppm (d, 2F); ESI-MS: $m / z$ : 975.5; UVvis (THF): $\lambda \max 408,503,543,584$, and $634 \mathrm{~nm}$.

\section{Cyclic voltammetry}

All electrochemical measurements were obtained by using a CHI760D potentiostat, with $0.1 \mathrm{M} \mathrm{TBAPF}_{6}$ as the supporting electrolyte. The electrolyte and tosic acid were placed under vacuum and oven dried prior to use. All cyclic voltammograms were obtained in a dry $\mathrm{N}_{2}$-filled glovebox, using a $4 \mathrm{~mm}$ diameter glassy carbon working electrode, a Pt mesh auxiliary counter electrode, and an $\mathrm{Ag} / \mathrm{Ag}^{+}$reference electrode. Ferrocene (Fc) was added after each measurement as an internal standard.

\section{Controlled-potential electrolysis and $\mathrm{H}_{2}$ detection}

Controlled-potential electrolysis was done in a custom-built two-compartment gas-tight electrochemical cell under an argon atmosphere. One part of the cell contains: (I) a carbon rod working electrode ( $3 \mathrm{~mm}$ diameter and $0.95 \mathrm{~mm}$ length); (II) an $\mathrm{Ag} / \mathrm{Ag}^{+}$reference electrode; (III) a gas inlet and gas outlet. The other part of the cell contains a Pt auxiliary wire counter electrode and a gas outlet. The working and counter electrodes are separated through a glass frit. Electrolysis was carried out at $-1.7 \mathrm{~V}$ vs. $\mathrm{Fc} / \mathrm{Fc}^{+}$in THF, containing $0.1 \mathrm{M} \mathrm{TBAPF}_{6}$ and $10 \mathrm{mM}$ tosic acid with and without adding the catalyst.

\section{Spectroelectrochemistry}

Spectroelectrochemistry was performed using an optical transparent $1 \mathrm{~mm}$ thin-layer spectroelectrochemical quartz cell containing an $\mathrm{Au}$ gauze working electrode, a non-aqueous $\mathrm{Ag} /$ $\mathrm{Ag}^{+}$reference electrode and a Pt wire counter electrode. The absorption spectra were recorded using a UV-vis spectrophotometer while the bulk electrolysis was performed using the CHI760D potentiostat. Solutions of 1 containing $0.1 \mathrm{M} \mathrm{TBAPF}_{6}$ with and without acid were prepared and degassed with $\mathrm{N}_{2}$ before each measurement. The changes of the UV-vis spectra were recorded at one second intervals for 10 minutes at different applied potentials.

\section{Other physical methods}

${ }^{1} \mathrm{H}$ NMR and ${ }^{19} \mathrm{~F}$ NMR spectra were recorded on a JEOL $600 \mathrm{MHz}$ NMR spectrometer. The proton NMR spectrum was referenced to the residual deuterated solvent signal as an internal calibration $\left(\mathrm{C}_{6} \mathrm{D}_{6}=7.16 \mathrm{ppm}\right)$. The UV-vis spectra were recorded on a SEC2000 spectra system equipped with VISUAL SPECTRA 2.1 software.

\section{Computational details}

The molecular geometries of the free base porphyrin and porphyrin derivatives (Scheme 1) were optimized using density functional theory (DFT). The DFT method employed was Becke's ${ }^{32}$ three parameter hybrid exchange functional, coupled with the Lee-YangParr $^{33}$ nonlocal correlation functional (B3LYP) for all calculations. The 6-31+ $\mathrm{G}^{34,35}$ Pople basis set, as implemented in Gaussian 09, was used for all atoms. ${ }^{36}$ Zero point energies and thermodynamic data were calculated at $298.15 \mathrm{~K}$ and $1 \mathrm{~atm}$ by performing frequency calculations. Calculations were performed on the optimized gasphase geometries using the solvation model based on density (SMD) as implemented in the Gaussian 09 suite..$^{37-39}$

In order to ease the computational expense, a model in which the pentafluorophenyl groups are replaced with chlorine atoms was employed. This substitution is reasonable due to the similar electron-withdrawing ability of $\mathrm{Cl}$ compared to that of $-\mathrm{C}_{6} \mathrm{~F}_{5}$ as supported by their Hammett substitution constants (Table $\mathrm{S} 2 \dagger$ ). We followed several theoretical models ${ }^{22,40-49}$ for the determination of thermodynamic quantities such as reduction potentials and $\mathrm{p} K_{\mathrm{a}} \mathrm{s}$ so as to give insight into the hydrogen evolution mechanism.

\section{Calculation of reduction free energies}

From a Born-Haber thermodynamic cycle (Scheme 2), we can associate the reaction free energies with the gas-phase and solvation energies using eqn (1):

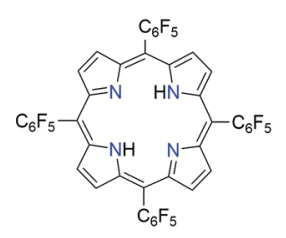

[1]

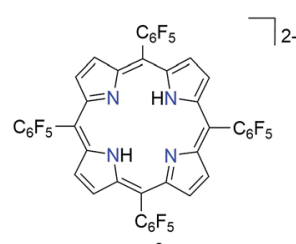

$[1]^{2-}$
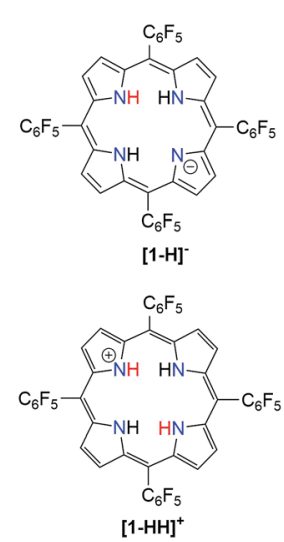

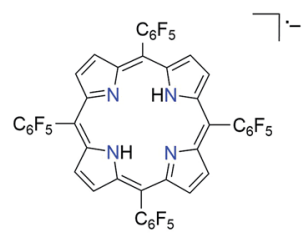

$[1]^{-}$
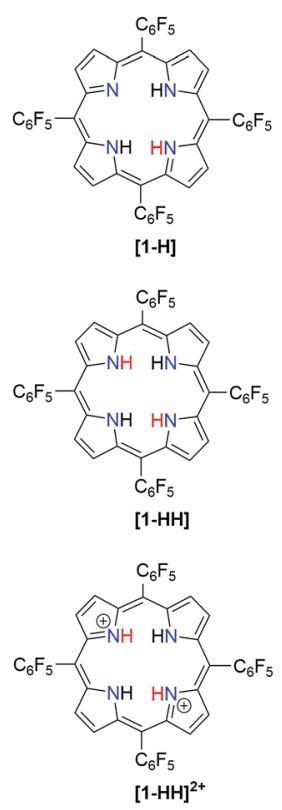

Scheme 1 Porphyrin derivatives involved in the proposed mechanistic pathways for hydrogen generation. 


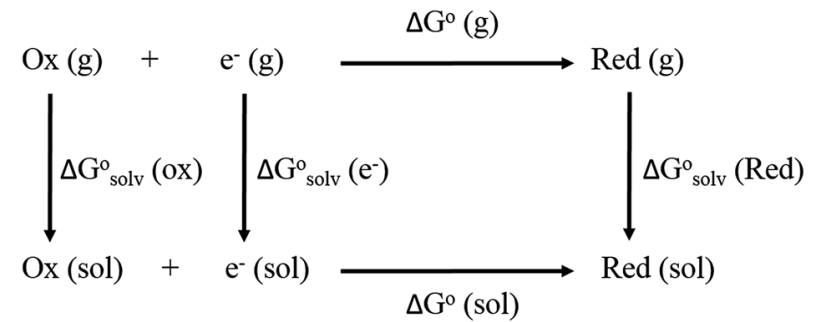

Scheme 2 Born-Haber thermodynamic cycle for the calculation of the free energy of reduction.

$$
\Delta G_{\text {(sol) }}^{\circ}=\Delta G_{(\mathrm{g})}^{\circ}+\Delta G_{\text {solv }}^{\circ}(\mathrm{Red})-\Delta G_{\text {solv }}^{\circ}(\mathrm{Ox})-\Delta G_{\text {solv }}^{\circ}\left(\mathrm{e}^{-}\right)
$$

where $\Delta G_{\text {solv }}^{\circ}($ Red $)$ and $\Delta G_{\text {solv }}^{\circ}(\mathrm{Ox})$ represent the free energies upon solvation for both the reduced and the oxidized species, $\Delta G_{\text {solv }}^{\circ}\left(\mathrm{e}^{-}\right)$the contribution of the electron to the solvation free energy, and $\Delta G_{(\mathrm{g})}^{\circ}$ the free energy of the reaction in the gas phase. We can calculate the last value with the expression $\Delta G_{(\mathrm{g})}^{\circ}=\Delta H_{(\mathrm{g})}^{\circ}-T \Delta S_{(\mathrm{g})}^{\circ}$.

Calculation of $\Delta G_{(\mathrm{sol})}^{\circ}$, allows the determination of redox potentials using eqn (2):

$$
E^{\circ}=\left(-\Delta G_{\mathrm{sol}}^{\circ} / n F\right)+E_{\mathrm{ref}}^{\circ}
$$

where $E^{\circ}$ is the standard reduction potential, $F$ is the Faraday constant and $n$ is the number of electrons involved in the redox reaction. In order to allow a direct comparison of calculated $v s$. experimental data, the redox potentials reported are referenced to the ferrocene/ferrocenium $\left(\mathrm{Fc} / \mathrm{Fc}^{+}\right)$couple.

\section{Calculation of proton dissociation free energies}

The direct calculation of reaction free energies in solution cannot be performed because the free energy of the solvated proton is difficult to calculate with accuracy. In order to calculate the thermodynamic value, we need to consider a protonexchange reaction between a reference compound ( $\mathrm{AH})$ and the free base porphyrin (1):

$$
\mathrm{A}^{-}+1-\mathrm{H}^{+} \rightarrow \mathrm{AH}+1
$$

Herein, we define the free energy change of reaction (3) as $\Delta G_{(\mathrm{sol})}^{\circ}$. To calculate $\Delta G_{(\text {sol })}^{\circ}$, we must relate it to the free energy in the gas phase using the thermodynamic cycle depicted in Scheme 3, obtaining the following equation:

$$
\begin{aligned}
\Delta G_{\text {(sol })}^{\circ}=\Delta G_{(\mathrm{g})}^{\circ} & +\Delta G_{\text {solv }}^{\circ}(\mathrm{AH})+\Delta G_{\text {solv }}^{\circ}(1) \\
& -\Delta G_{\text {solv }}^{\circ}\left(\mathrm{A}^{-}\right)-\Delta G_{\text {solv }}^{\circ}\left(1-\mathrm{H}^{+}\right)
\end{aligned}
$$

where $\Delta G_{\text {solv }}^{\circ}\left(\mathrm{A}^{-}\right), \Delta G_{\text {solv }}^{\circ}\left(1-\mathrm{H}^{+}\right), \Delta G_{\text {solv }}^{\circ}(\mathrm{AH})$ and $\Delta G_{\text {solv }}^{\circ}(1)$ are the free energies upon solvation of the referenced conjugated base, the protonated porphyrin, the referenced acid and the porphyrin, respectively. We can calculate $\Delta G_{(\mathrm{g})}^{\circ}$, using the expression $\Delta G_{(g)}^{\circ}=\Delta H_{(\mathrm{g})}^{\circ}-T \Delta S_{(\mathrm{g})}^{\circ}$. The $\mathrm{p} K_{\mathrm{a}}$ can be calculated from $\Delta G_{\text {sol }}^{\circ}$ using:

$$
\mathrm{p} K_{\mathrm{a}}=\left(\Delta G_{\mathrm{sol}}^{\circ} / 2.303 R T\right)+\mathrm{p} K_{\mathrm{a}(\mathrm{ref})}
$$

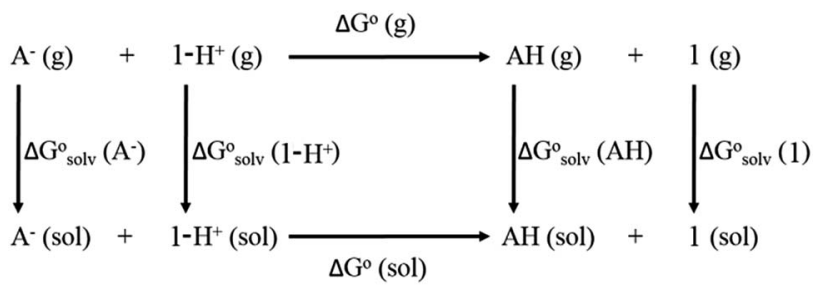

Scheme 3 Born-Haber thermodynamic cycle for the calculation of the free energy of proton transfer.

where $R$ is the gas constant, $T$ is the temperature $(298.15 \mathrm{~K})$, and $\mathrm{p} K_{\mathrm{a}(\mathrm{ref})}$ is the experimentally reported $\mathrm{p} K_{\mathrm{a}}$ of the reference reaction. Since the deprotonation of acetic acid has been studied in THF and the $\mathrm{p} K_{\mathrm{a}}$ value is available, we chose this reaction as our reference. ${ }^{50}$

\section{Results and discussion}

Cyclic voltammetry experiments were conducted in THF in order to assess the electrocatalytic activity of $\mathbf{1}$. In the absence of acid, 1 features two reversible one-electron reductions at $E_{1 / 2}=$ $-1.14 \mathrm{~V}$ and $E_{1 / 2}=-1.54 \mathrm{~V} v s . \mathrm{Fc} / \mathrm{Fc}^{+}$that yield the porphyrin radical anion $[\mathbf{1}]^{--}$and the dianion species $[\mathbf{1}]^{2-}$, respectively (Fig. 1). Upon successive addition of tosic acid, the first reduction wave of 1 remains unchanged, while a catalytic wave appears at a potential near $-1.31 \mathrm{~V} v s$. $\mathrm{Fc} / \mathrm{Fc}^{+}$, which occurs before the second reduction wave of 1 at $-1.54 \mathrm{~V}$. This indicates that protonation of this porphyrin is not possible under these conditions prior to the one-electron reduction. The reduction potential of $\mathrm{H}^{+} / \mathrm{H}_{2}\left(\mathrm{EH}^{+}\right)$with tosic acid in THF is $-0.605 \mathrm{~V} v s$. $\mathrm{Fc} / \mathrm{Fc}^{+}$, which corresponds to an overpotential of $1.02 \mathrm{~V} .^{51,52}$ Notably, addition of acid without the presence of 1 shows a negligible current increase (Fig. S1 $\dagger$ ). As a control, a second metal-free porphyrin, meso-tetraphenylporphyrin was also evaluated as a HER electrocatalyst using tosic acid as the proton

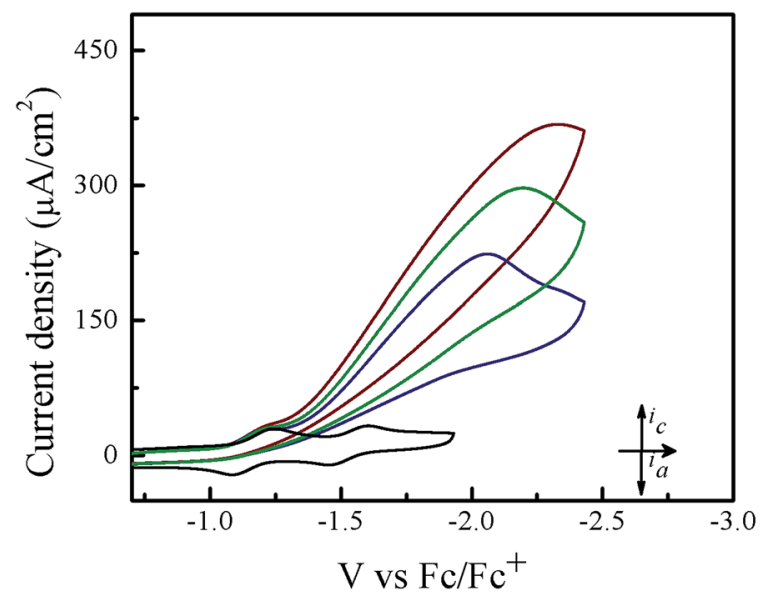

Fig. 1 Cyclic voltammograms of $0.1 \mathrm{mM} 1$ in a solution containing $0.1 \mathrm{M} \mathrm{TBAPF}_{6}$ with and without tosic acid: (from bottom to top): 0 equiv. acid, 4 equiv. acid, 9 equiv. acid, and 12 equiv. acid. Scan rate: $100 \mathrm{mV} \mathrm{s}^{-1}$; a glassy carbon working electrode. 


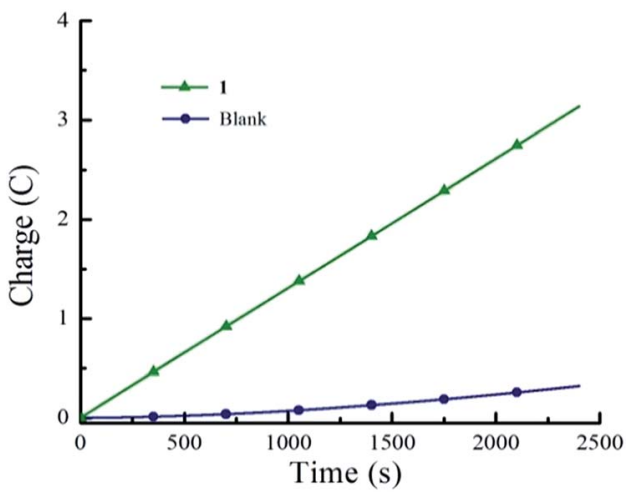

Fig. 2 Controlled-potential electrolysis experiments containing $1 \mathrm{mM}$ 1, $0.1 \mathrm{M} \mathrm{TBAPF}_{6}$ and $10 \mathrm{mM}$ tosic acid on a carbon rod electrode: ( $\mathbf{\Delta}$ ) $10 \mathrm{mM}$ tosic acid with $1 \mathrm{mM} \mathrm{1}$, and (0) $10 \mathrm{mM}$ tosic acid without 1. Potential: $-1.7 \mathrm{~V}$ vs. Fc/Fc ${ }^{+}$

source. The electrocatalytic current achieved using this porphyrin was very low (onset potential: $-1.89 \mathrm{~V} v s$. $\mathrm{Fc} / \mathrm{Fc}^{+}$; peak current: $18 \mu \mathrm{A}$. see Fig. S3†).

Hydrogen gas production was confirmed by gas chromatography through the evaluation of the gas product obtained from controlled potential electrolysis. Fig. 2 depicts the dependence of accumulated charge over 40 minutes, resulting in $3.2 \mathrm{C}$ of charge corresponding to $90 \%$ faradaic efficiency (see Experimental section for full experimental details).

In order to investigate whether there is a formation of a heterogeneous metal-free porphyrin thin film on the working electrode, which can be responsible for HER activity, cyclic voltammograms were obtained using a glassy carbon electrode after performing controlled-potential electrolysis. Two glassy carbon electrodes were subjected to $1 \mathrm{~h}$ of electrolysis in the presence of 1 with and without tosic acid. After the experiment, the electrodes were rinsed with THF and dried in air. Then they were exposed to fresh acidic solutions $(1.5 \mathrm{mM})$ without the addition of $\mathbf{1}$. In neither case the working electrode shows any increase of catalytic current (Fig. S6 and S7†), implying that 1 does not adsorb on the working electrode surface during our electrochemical studies.

HER kinetics were measured by foot-of-the-wave analysis (FOWA). The observed rate constant $\left(k_{\text {obs }}\right)$ was calculated from the slope of the linear region near the foot of the wave (see the $\mathrm{ESI} \dagger$ for full experimental details). The calculated $k_{\mathrm{obs}}$ are displayed in Table S3, $\dagger$ showing values of $0.528,0.742$ and $0.891 \mathrm{~s}^{-1}$ at acid concentrations $\left(\left[\mathrm{H}^{+}\right]\right)$of $0.4,0.9$ and $1.2 \mathrm{mM}$ respectively. Plotting $k_{\mathrm{obs}}$ versus $\left[\mathrm{H}^{+}\right]$gives a linear relationship (Fig. S9†), suggesting a first order dependence of $\left[\mathrm{H}^{+}\right]$. A kinetic isotope effect (KIE) of 1.16 was observed when using deuterated tosic acid $\left(\mathrm{C}_{7} \mathrm{H}_{7} \mathrm{SO}_{3} \mathrm{D}\right)$.

The HER mechanism of $\mathbf{1}$ was probed through spectroscopic techniques. When two protons and two electrons are involved, several different pathways can be followed in order to generate hydrogen. The following possible sequential mechanistic steps were considered: E-E-P-P, E-P-E-P, E-P-P-E, P-E-E-P, P-E-P-E, and $\mathrm{P}-\mathrm{P}-\mathrm{E}-\mathrm{E}$, where $\mathrm{E}$ stands for reduction and $\mathrm{P}$ stands for protonation. In THF, 1 exhibits a narrow and intense absorbance

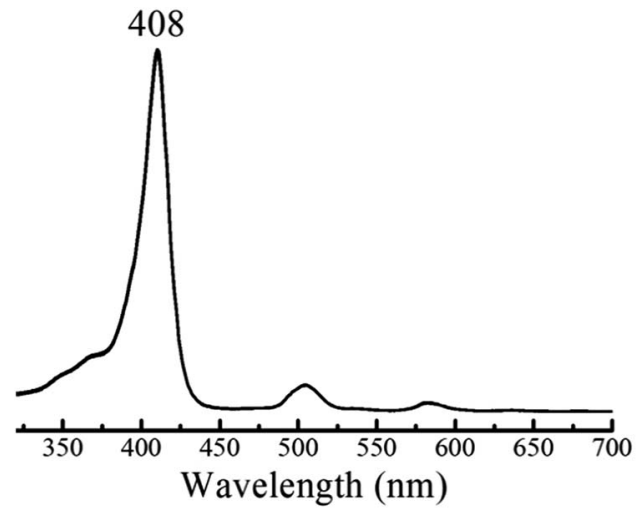

Fig. 3 UV-Vis spectrum of 1 in THF containing 0.1 M TBAPF 6 before and after titrating with tosic acid.

in the typical Soret (375-425 $\mathrm{nm}$ ) region and four small Q-bands between 470 and $650 \mathrm{~nm}$. Upon titration of tosic acid, the electronic spectrum remains constant (Fig. 3). This indicates that in THF, tosic acid is not strong enough to protonate 1, suggesting that the first step of hydrogen generation is a reduction.

Fig. 4 shows the spectral changes of 1 under different electrolysis conditions. The UV-vis spectrum of $\mathbf{1}$ upon controlled-potential bulk electrolysis at the potential of the first one-electron reduction of the porphyrin $\left(-1.35 \mathrm{~V} v s . \mathrm{Fc} / \mathrm{Fc}^{+}\right)$, shows a decrease of the Soret (408 nm) and Q-bands (503, 530, 584 , and $634 \mathrm{~nm}$ ); and the appearance of an absorption band at $436 \mathrm{~nm}$ along with an isosbestic point at $428 \mathrm{~nm}$. This new band can be attributed to the generation of the radical anion $[1]^{\cdot-}$ (Fig. 4a). Under the same controlled potential of $-1.35 \mathrm{~V} v s . \mathrm{Fc} /$ $\mathrm{Fc}^{+}$but in the presence of tosic acid, the band at $436 \mathrm{~nm}$ corresponding to the radical anion $[1]^{\cdot-}$ is also seen but the isosbestic point at $428 \mathrm{~nm}$ disappears as a function of time (Fig. 4b). This implies that in addition to the generation of the radical anion $[\mathbf{1}]^{\cdot-}$, other chemical species are also produced. Since the only condition changed between Fig. $4 \mathrm{a}$ and $\mathrm{b}$ is the addition of acid, the second step of the catalytic cycle should be assigned to protonation after the one-electron reduction.

When performing bulk electrolysis at the potential above the second electron reduction wave $\left(-1.7 \mathrm{~V} v s . \mathrm{Fc} / \mathrm{Fc}^{+}\right)$without the presence of acid, the recorded spectrum (Fig. 4c) shows an immediate decay of the Soret absorbance coupled to an increase of a broad absorbance at $454 \mathrm{~nm}$, a new band at $369 \mathrm{~nm}$ and another new band in the ultraviolet region (300 nm), along with an isosbestic point at $425 \mathrm{~nm}$. This features the transformation from the free-base porphyrin [1] into the dianion species $[\mathbf{1}]^{2-}$. When bulk electrolysis was conducted at the same potential $\left(-1.7 \mathrm{~V} v s . \mathrm{Fc} / \mathrm{Fc}^{+}\right)$in the presence of tosic acid, the absorbance belonging to the dianion $[\mathbf{1}]^{2-}$ is not observed and only a decrease of the Soret absorbance occurs (Fig. 4d). However, the rate of decay of the Soret band in the presence of acid is slower compared to that without acid (Fig. S12 $\dagger$ ). This suggests that 1 is regenerated upon $\mathrm{H}_{2}$ production. Overall these spectroscopy studies show that the first and second events of the mechanism of hydrogen generation with 1 in the presence of tosic acid are reduction and protonation, respectively. 

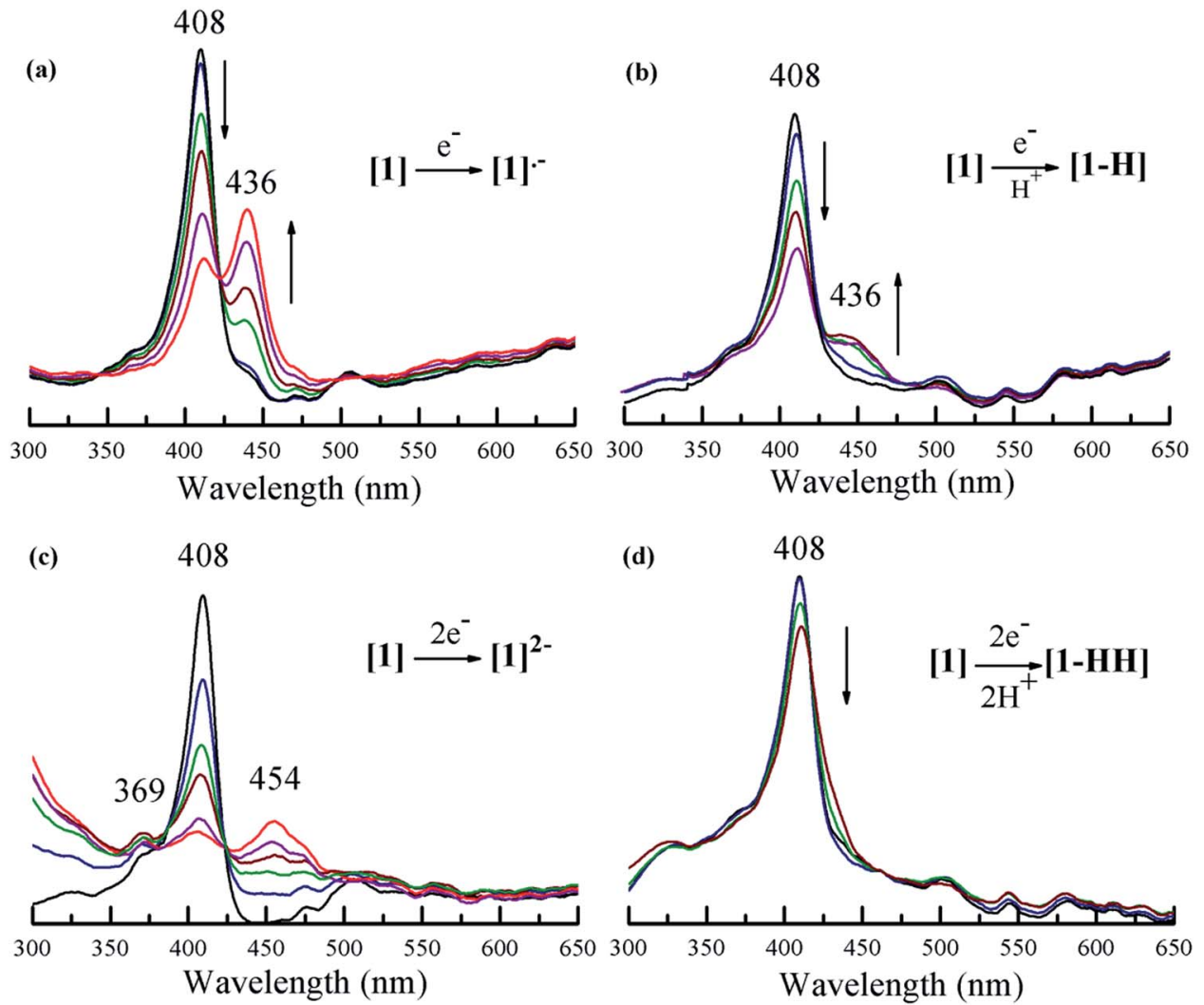

Fig. 4 UV-vis spectroelectrochemistry of 1 in the absence and in the presence of tosic acid containing $0.1 \mathrm{M} \mathrm{TBAPF}$ in THF: (a) 1 at $-1.35 \mathrm{~V}$; (b) 1 containing tosic acid at $-1.35 \mathrm{~V}$; (c) 1 at $-1.7 \mathrm{~V}$; (d) 1 containing tosic acid at $-1.7 \mathrm{~V}$ (potentials are referred to $\mathrm{Fc} / \mathrm{Fc}^{+}$).

Thermodynamic theoretical calculations were also performed to provide further insight into the next steps of hydrogen generation. Scheme 4 shows the three different pathways for hydrogen generation in THF after the first reduction, and Fig. 5 shows the calculated relative free energies corresponding to each of these pathways. The calculated relative free energies in Fig. 5 are plotted relative to the tosic acid/ dihydrogen $\left(\mathrm{TsOH} / \mathrm{H}_{2}\right)$ couple.

The relative free energy difference between $[\mathbf{1}]$ and $[\mathbf{1}]^{--}$is calculated to be $12.8 \mathrm{kcal} \mathrm{mol}^{-1}(+0.556 \mathrm{eV})$ which corresponds to a potential of $-1.06 \mathrm{~V} v s . \mathrm{Fc} / \mathrm{Fc}^{+}$. Upon the first reduction, [1] ${ }^{\cdot-}$ can follow two possible paths: it can be either further reduced to $[\mathbf{1}]^{2-}$ or protonated at the $\mathrm{N}$ core using tosic acid to yield $[\mathbf{1}-\mathbf{H}]$. Protonation to generate $[\mathbf{1}-\mathbf{H}]$ is thermodynamically favored with a relative free energy of $+2.39 \mathrm{kcal} \mathrm{mol}^{-1}(+0.104 \mathrm{eV})$, compared to going uphill $+36.3 \mathrm{kcal} \mathrm{mol}^{-1}(+1.57 \mathrm{eV})$ to form $[1]^{2-}$.

The calculated relative $\mathrm{p} K_{\mathrm{a}}$ for the deprotonation of $[\mathbf{1}-\mathbf{H}]$ is 20.3. Since the $\mathrm{p} K_{\mathrm{a}}$ of tosic acid in THF is predicted to be 11.8 , the reduced porphyrin is likely to get protonated. The first two steps of the proposed mechanism (E-P) are in agreement with our experimental observations. The next step can be either electron transfer or protonation, to yield $[\mathbf{1}-\mathbf{H}]^{-}$or $[\mathbf{1}-\mathbf{H H}]^{+}$, respectively. While we cannot experimentally discern between these two pathways, $[\mathbf{1}-\mathbf{H}]^{-}$is calculated to be thermodynamically favored by $8.91 \mathrm{kcal} \mathrm{mol}^{-1}$ when compared to generating $[\mathbf{1}-\mathbf{H H}]^{+}$. The following step yields $[\mathbf{1}-\mathbf{H H}]$, which putatively produces $\mathrm{H}_{2}$, and closes the cycle. The overall proposed mechanism is described in Scheme 5 . Calculated relative $\mathrm{p} K_{\mathrm{a}} \mathrm{s}$ and redox potentials for all possible mechanistic pathways for $\mathrm{H}_{2}$ generation are presented in Table S3.†

Pathway 1

$$
\begin{aligned}
& {[1]+\mathrm{e}^{-} \longrightarrow[1]^{-}} \\
& {[1]^{-}+\mathrm{HA} \longrightarrow[1-\mathrm{H}]+\mathrm{A}^{-}} \\
& {[1-\mathrm{H}]+\mathrm{HA} \longrightarrow[1-\mathrm{HH}]^{+}+\mathrm{A}^{-}} \\
& {[1-\mathrm{HH}]^{+}+\mathrm{e}^{-} \longrightarrow[1-\mathrm{HH}]} \\
& {[1-\mathrm{HH}] \longrightarrow[1]+\mathrm{H}_{2}}
\end{aligned}
$$

Pathway 2

$$
\begin{aligned}
& {[1]+\mathrm{e}^{-} \longrightarrow[1]^{-}} \\
& {[1]^{-}+\mathrm{HA} \longrightarrow[1-\mathrm{H}]+\mathrm{A}^{-}} \\
& {[1-\mathrm{H}]+\mathrm{e}^{-} \longrightarrow[1-\mathrm{H}]^{-}} \\
& {[1-\mathrm{H}]^{-}+\mathrm{HA} \longrightarrow[1-\mathrm{HH}]+\mathrm{A}^{-}} \\
& {[1-\mathrm{HH}] \longrightarrow[1]+\mathrm{H}_{2}}
\end{aligned}
$$

Pathway 3

$$
\begin{aligned}
& {[1]+\mathrm{e}^{-} \longrightarrow[1]^{-}} \\
& {[1]^{-}+\mathrm{e}^{-} \longrightarrow[1]^{2-}} \\
& {[1]^{2-}+\mathrm{HA} \longrightarrow[1-\mathrm{H}]^{-}+\mathrm{A}^{-}} \\
& {[1-\mathrm{H}]^{-}+\mathrm{HA} \longrightarrow[1-\mathrm{HH}]+\mathrm{A}^{-}} \\
& {[1-\mathrm{HH}] \longrightarrow[1]+\mathrm{H}_{2}}
\end{aligned}
$$

Scheme 4 Mechanistic pathways proposed for hydrogen generation in THF, with tosic acid as the proton source. 


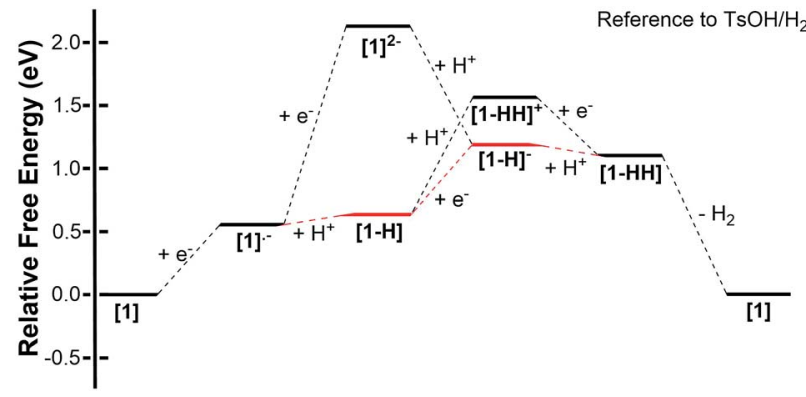

Fig. 5 Free energy diagram of $\mathrm{H}_{2}$ evolution catalyzed using 1 in THF with tosic acid. The free energies were calculated using the BornHaber cycles shown in Schemes 2 and 3, and these are plotted relative to the tosic acid/dihydrogen $\left(\mathrm{TsOH} / \mathrm{H}_{2}\right)$ couple.

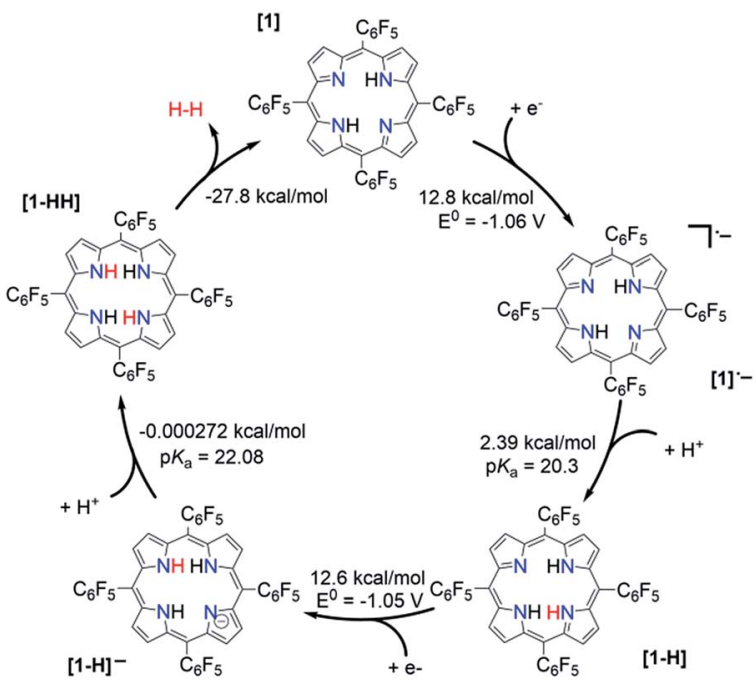

Scheme 5 Proposed catalytic cycle for $\mathrm{H}_{2}$ evolution, following an $\mathrm{E}-$ $\mathrm{P}-\mathrm{E}-\mathrm{P}$ mechanism, with THF as solvent.

\section{Conclusion}

In conclusion, we have studied the electrocatalytic generation of $\mathrm{H}_{2}$ using a metal-free perfluorinated porphyrin. The catalytic activity was studied through cyclic voltammetry and controlled-potential electrolysis. Hydrogen is produced electrochemically at $-1.31 \mathrm{~V} v s$. $\mathrm{Fc} / \mathrm{Fc}^{+}$in THF using tosic acid at $90 \%$ faradaic yield. Electronic spectra and spectroelectrochemical experiments combined with thermodynamic calculations using density functional theory computations suggest that the most favorable mechanistic process is an E-P-E-P sequence. This promising finding may contribute to open a new area for replacing noble metals with much more abundant organic compounds for the catalytic generation of hydrogen gas. It should be noted that this observed activity is limited to the meso-tetrapentafluorophenyl porphyrin with tosic acid and in THF as the solvent. We are currently working on the catalytic study of other substitution patterns (and other organic macrocycles) for the electrocatalytic production of hydrogen.

\section{Conflicts of interest}

The authors declare no conflicts of interest.

\section{Acknowledgements}

NRL acknowledges financial support from CONACYT (Mexico). We thank Prof. Daniel G. Nocera, Dr Dilek Dogutan, and Dr Maher for helpful discussions. This work was supported in part by NSF under award number CHE-1305124.

\section{Notes and references}

1 N. S. Lewis and D. G. Nocera, Proc. Natl. Acad. Sci. U. S. A., 2006, 103, 15729-15735.

2 J. A. Turner, Science, 2004, 305, 972-974.

3 M. G. Walter, E. L. Warren, J. R. McKone, S. W. Boettcher, Q. Mi, E. A. Santori and N. S. Lewis, Chem. Rev., 2010, 110, 6446-6473.

4 H. B. Gray, Nat. Chem., 2009, $1,7$.

5 D. Merki and X. Hu, Energy Environ. Sci., 2011, 4, 3878-3888.

6 P. Du and R. Eisenberg, Energy Environ. Sci., 2012, 5, 60126021.

7 W. T. Eckenhoff, W. R. McNamara, P. Du and R. Eisenberg, Biochim. Biophys. Acta Bioenerg., 2013, 1827, 958-973.

8 M. Wang, L. Chen and L. Sun, Energy Environ. Sci., 2012, 5, 6763-6778.

9 C. Baffert, V. Artero and M. Fontecave, Inorg. Chem., 2007, 46, 1817-1824.

10 J. F. Callejas, J. M. McEnaney, C. G. Read, J. C. Crompton, A. J. Biacchi, E. J. Popczun, T. R. Gordon, N. S. Lewis and R. E. Schaak, ACS Nano, 2014, 8, 11101-11107.

11 M. R. DuBois and D. L. DuBois, Chem. Soc. Rev., 2008, 38, 6272.

12 L. L. Efros, H. H. Thorp, G. W. Brudvig and R. H. Crabtree, Inorg. Chem., 1992, 31, 1722-1724.

13 T. F. Jaramillo, K. P. Jørgensen, J. Bonde, J. H. Nielsen, S. Horch and I. Chorkendorff, Science, 2007, 317, 100-102.

14 E. J. Popczun, C. G. Read, C. W. Roske, N. S. Lewis and R. E. Schaak, Angew. Chem., Int. Ed., 2014, 53, 5427-5430.

15 A. D. Wilson, R. H. Newell, M. J. McNevin, J. T. Muckerman, M. Rakowski DuBois and D. L. DuBois, J. Am. Chem. Soc., 2006, 128, 358-366.

16 Y. Zheng, Y. Jiao, Y. Zhu, L. H. Li, Y. Han, Y. Chen, A. Du, M. Jaroniec and S. Z. Qiao, Nat. Commun., 2014, 5, ncomms4783.

17 B. C. Patra, S. Khilari, R. N. Manna, S. Mondal, D. Pradhan, A. Pradhan and A. Bhaumik, ACS Catal., 2017, 7, 6120-6127.

18 T. Abe, F. Taguchi, H. Imaya, F. Zhao, J. Zhang and M. Kaneko, Polym. Adv. Technol., 1998, 9, 559-562.

19 I. Bhugun, D. Lexa and J.-M. Savéant, J. Am. Chem. Soc., 1996, 118, 3982-3983.

20 V. Grass, D. Lexa and J.-M. Savéant, J. Am. Chem. Soc., 1997, 119, 7526-7532.

21 C. H. Lee, D. K. Dogutan and D. G. Nocera, J. Am. Chem. Soc., 2011, 133, 8775-8777. 
22 D. K. Bediako, B. H. Solis, D. K. Dogutan, M. M. Roubelakis, A. G. Maher, C. H. Lee, M. B. Chambers, S. Hammes-Schiffer and D. G. Nocera, Proc. Natl. Acad. Sci. U. S. A., 2014, 111, 15001-15006.

23 B. H. Solis and S. Hammes-Schiffer, Inorg. Chem., 2014, 53, 6427-6443.

24 J. P. Collman, P. S. Wagenknecht and N. S. Lewis, J. Am. Chem. Soc., 1992, 114, 5665-5673.

25 X. Hu, B. S. Brunschwig and J. C. Peters, J. Am. Chem. Soc., 2007, 129, 8988-8998.

26 S. C. Marinescu, J. R. Winkler and H. B. Gray, Proc. Natl. Acad. Sci. U. S. A., 2012, 109, 15127-15131.

27 H. N. Fonda, J. V. Gilbert, R. A. Cormier, J. R. Sprague, K. Kamioka and J. S. Connolly, J. Phys. Chem., 1993, 97, 7024-7033.

28 Handbook of Porphyrin Science (Volumes 31-35), http:// www.worldscientific.com/worldscibooks/10.1142/8560, accessed January 24, 2017.

29 S. Aronoff, J. Phys. Chem., 1958, 62, 428-431.

30 F. Hibbert and K. P. P. Hunte, J. Chem. Soc., Perkin Trans. 2, 1977, 1624-1628.

31 J. S. Lindsey, H. C. Hsu and I. C. Schreiman, Tetrahedron Lett., 1986, 27, 4969-4970.

32 A. D. Becke, J. Chem. Phys., 1993, 98, 5648-5652.

33 C. Lee, W. Yang and R. G. Parr, Phys. Rev. B: Condens. Matter Mater. Phys., 1988, 37, 785-789.

34 M. J. Frisch, J. A. Pople and J. S. Binkley, J. Chem. Phys., 1984, 80, 3265-3269.

35 P. C. Hariharan and J. A. Pople, Theor. Chim. Acta, 1973, 28, 213-222.

36 M. J. Frisch, G. W. Trucks, H. B. Schlegel, G. E. Scuseria, M. A. Robb, J. R. Cheeseman, G. Scalmani, V. Barone, B. Mennucci, G. A. Petersson, H. Nakatsuji, M. Caricato, X. Li, H. P. Hratchian, A. F. Izmaylov, J. Bloino, G. Zheng, J. L. Sonnenberg, M. Hada, M. Ehara, K. Toyota, R. Fukuda, J. Hasegawa, M. Ishida, T. Nakajima, Y. Honda, O. Kitao, H. Nakai, T. Vreven, J. A. Montgomery Jr, J. E. Peralta, F. Ogliaro, M. Bearpark, J. J. Heyd, E. Brothers, K. N. Kudin, V. N. Staroverov, R. Kobayashi, J. Normand, K. Raghavachari, A. Rendell, J. C. Burant,
S. S. Iyengar, J. Tomasi, M. Cossi, N. Rega, J. M. Millam, M. Klene, J. E. Knox, J. B. Cross, V. Bakken, C. Adamo, J. Jaramillo, R. Gomperts, R. E. Stratmann, O. Yazyev, A. J. Austin, R. Cammi, C. Pomelli, J. W. Ochterski, R. L. Martin, K. Morokuma, V. G. Zakrzewski, G. A. Voth, P. Salvador, J. J. Dannenberg, S. Dapprich, A. D. Daniels, Ö. Farkas, J. B. Foresman, J. V. Ortiz, J. Cioslowski and D. J. Fox, Gaussian 09, Revision C.01, Gaussian, Inc., Wallingford, CT, 2010.

37 R. Cammi, B. Mennucci and J. Tomasi, J. Phys. Chem. A, 2000, 104, 4690-4698.

38 R. Cammi, B. Mennucci and J. Tomasi, J. Phys. Chem. A, 1998, 102, 870-875.

39 A. V. Marenich, C. J. Cramer and D. G. Truhlar, J. Phys. Chem. B, 2009, 113, 6378-6396.

40 B. H. Solis, A. G. Maher, T. Honda, D. C. Powers, D. G. Nocera and S. Hammes-Schiffer, ACS Catal., 2014, 4, 4516-4526.

41 B. H. Solis and S. Hammes-Schiffer, Inorg. Chem., 2014, 53, 6427-6443.

42 B. H. Solis and S. Hammes-Schiffer, J. Am. Chem. Soc., 2011, 133, 19036-19039.

43 H. Tang and M. B. Hall, J. Am. Chem. Soc., 2017, 139, 1806518070.

44 B. H. Solis, A. G. Maher, D. K. Dogutan, D. G. Nocera and S. Hammes-Schiffer, Proc. Natl. Acad. Sci. U. S. A., 2016, 113, 485-492.

45 K. Aidas, K. Lanevskij, R. Kubilius, L. Juška, D. Petkevičius and P. Japertas, J. Comput. Chem., 2015, 36, 2158-2167.

46 B. H. Solis, A. G. Maher, T. Honda, D. C. Powers, D. G. Nocera and S. Hammes-Schiffer, ACS Catal., 2014, 4, 4516-4526.

47 L. E. Fernandez, S. Horvath and S. Hammes-Schiffer, J. Phys. Chem. C, 2012, 116, 3171-3180.

48 B. H. Solis and S. Hammes-Schiffer, Inorg. Chem., 2011, 50, 11252-11262.

49 J. Ho and M. L. Coote, Theor. Chem. Acc., 2010, 125, 3.

50 F. Ding, J. M. Smith and H. Wang, J. Org. Chem., 2009, 74, 2679-2691.

51 J. A. S. Roberts and R. M. Bullock, Inorg. Chem., 2013, 52, 3823-3835.

52 A. M. Appel and M. L. Helm, ACS Catal., 2014, 4, 630-633. 